\title{
Complete genome sequencing of three human clinical isolates of Staphylococcus caprae reveals virulence factors similar to those of S. epidermidis and S. capitis
}

Shinya Watanabe, Yoshifumi Aiba, Xin-Ee Tan, Feng-Yu Li, Tanit Boonsiri, Kanate Thitiananpakorn, Bintao Cui, Yusuke Sato'o, Kotaro Kiga, Teppei Sasahara and Longzhu Cui ${ }^{*}$

\begin{abstract}
Background: Staphylococcus caprae is an animal-associated bacterium regarded as part of goats' microflora. Recently, S. caprae has been reported to cause human nosocomial infections such as bacteremia and bone and joint infections. However, the mechanisms responsible for the development of nosocomial infections remain largely unknown. Moreover, the complete genome sequence of $S$. caprae has not been determined.

Results: We determined the complete genome sequences of three methicillin-resistant S. caprae strains isolated from humans and compared these sequences with the genomes of S. epidermidis and S. capitis, both of which are closely related to $S$. caprae and are inhabitants of human skin capable of causing opportunistic infections. The genomes showed that S. caprae JMUB145, JMUB590, and JMUB898 strains contained circular chromosomes of 2,618,380, 2,629,173, and 2,598,513 bp, respectively. JMUB145 carried type V SCCmec, while JMUB590 and JMUB898 had type IVa SCCmec. A genome-wide phylogenetic SNP tree constructed using 83 complete genome sequences of 24 Staphylococcus species and 2 S. caprae draft genome sequences confirmed that S. caprae is most closely related to $S$. epidermidis and S. capitis. Comparative complete genome analysis of eight $S$. epidermidis, three S. capitis and three $S$. caprae strains revealed that they shared similar virulence factors represented by biofilm formation genes. These factors include wall teichoic acid synthesis genes, poly-gamma-DL-glutamic acid capsule synthesis genes, and other genes encoding nonproteinaceous adhesins. The 17 proteinases/adhesins and extracellular proteins known to be associated with biofilm formation in S. epidermidis were also conserved in these three species, and their biofilm formation could be detected in vitro. Moreover, two virulence-associated gene clusters, the type VII secretion system and capsular polysaccharide biosynthesis gene clusters, identified in S. aureus were present in S. caprae but not in S. epidermidis and S. capitis genomes.

Conclusion: The complete genome sequences of three methicillin-resistant $S$. caprae isolates from humans were determined for the first time. Comparative genome analysis revealed that $S$. caprae is closely related to $S$. epidermidis and S. capitis at the species level, especially in the ability to form biofilms, which may lead to increased virulence during the development of $\mathrm{S}$. caprae infections.
\end{abstract}

Keywords: Staphylococcus caprae, Staphylococcus epidermidis, Staphylococcus capitis, Complete whole genome sequence, Biofilm formation, Nosocomial infection, Adhesin, SCCmec

\footnotetext{
* Correspondence: longzhu@jichi.ac.jp

Division of Bacteriology, Department of Infection and Immunity, Faculty of

Medicine, Jichi Medical University, 3311-1, Yakushiji, Shimotsuke-shi, Tochigi

329-0498, Japan
}

(c) The Author(s). 2018 Open Access This article is distributed under the terms of the Creative Commons Attribution 4.0 International License (http://creativecommons.org/licenses/by/4.0/), which permits unrestricted use, distribution, and reproduction in any medium, provided you give appropriate credit to the original author(s) and the source, provide a link to the Creative Commons license, and indicate if changes were made. The Creative Commons Public Domain Dedication waiver (http://creativecommons.org/publicdomain/zero/1.0/) applies to the data made available in this article, unless otherwise stated. 


\section{Background}

Staphylococci are major components of the normal microflora in human and animals [1, 2]. Consistent with traditional culture-based analysis, recent microbiome analysis showed that the skin of healthy humans is predominantly colonized by Propionibacterium, Corynebacterium, and Staphylococcus [3-5]. Most of these skin inhabitants, including coagulase-negative staphylococci (CoNS), are considered harmless to healthy humans. In fact, these organisms protect against invasion by other more pathogenic or harmful organisms [6]. However, recent changes in population demographics, including elevated numbers of immunocompromised patients, elderly adults and premature newborns, as well as the increasing use of inserted foreign bodies, have been reported to contribute to the large variety of CoNS infections [7]. In clinical settings, CoNS have rarely been classified at the species level. Clinical isolates of staphylococci are routinely differentiated between the highly virulent species Staphylococcus aureus, which produces coagulase, and coagulase-negative CoNS. Thus, the real impact of minor isolated species of CoNS might be underreported [7]. Moreover, detailed classification of CoNS to species levels has revealed that less frequently isolated CoNS, which are considered less virulent or of animal origin, could cause infections if the patients have underlying conditions such as indwelling foreign bodies and/or immunosuppression [8].

Staphylococcus caprae is one of the animal-associated CoNS that usually colonizes skin and mammary glands of goats and sometimes causes goat mastitis [9]. $S$. caprae also causes zoonosis whereby $S$. caprae have been isolated from patients in close contact with goats/sheep, such as farm workers, sheep breeders and those who had been bitten by a goat [10]. However, S. caprae infections have recently been recognized as hospital-acquired infections since most $S$. caprae infections were related to medical care and were contracted in hospitals [10]. Reported S. caprae infections include bacteremia, acute otitis externa, bone and joint infections, and prosthetic infections [10-14]. However, the reasons why bacteria of animal origin cause nosocomial infections are not well understood.

Phylogenetic analysis using multilocus DNA sequence data (16S rRNA gene, dnaJ, rpoB, and tuf gene fragments) estimated that $S$. caprae belongs to the "Epidermidis cluster group," which includes S. epidermidis, $S$. capitis subsp. capitis, S. capitis subsp. urealyticus, and $S$. saccharolyticus [15]. S. epidermidis is the most frequently isolated staphylococcal species from a wide range of human skin niches such as head, legs, and arms [7]. It is also known as one of the most common bacterial pathogens circulating in hospital settings and is the leading cause of nosocomial bloodstream and cardiovascular infections as well as infections associated with implanted medical devices [7, 16]. Since S. epidermidis, $S$. capitis, and $S$. caprae all belong to the epidermidis cluster group and cause hospital-acquired bloodstream and implant-associated infections, they are assumed to share the fundamental mechanisms responsible for the various nosocomial infections.

In this study, we determined the complete whole-genome sequences of three $S$. caprae strains isolated from patients with bloodstream or graft infections, or a nasal swab culture of an MRSA screening at hospital admission. To date, genome sequence data from more than 400 S. epidermidis, S. capitis, and S. caprae isolates are available in GenBank. However, since most of these genome sequences are draft genomes generated by de novo assembly of short reads, repetitive sequences are not completely determined. Therefore, we thought that complete genome sequence data are essential for the analysis of genes containing repeat regions, such as the gene encoding a surface adhesin of S. epidermidis (fibrinogen-binding protein Fbe), which plays an important role in biofilm formation and devise-related infections.

\section{Results and discussion}

\section{General features of $S$. caprae genomes}

We determined complete whole-genome sequences of three methicillin-resistant $S$. caprae strains isolated from humans. Two draft genome sequences of S. caprae 9557 and M23864:W1 strains were recently determined, and genome comparison analysis of $S$. epidermidis, S. capitis, and $S$. caprae was carried out using two complete genomes of S. epidermidis and S. capitis and two draft genomes of $S$. capitis and $S$. caprae $[17,18]$. However, it is difficult to elucidate the complete features of Staphylococcus chromosome structures and genes containing repeats with draft genome sequence analysis. For example, the draft genome sequence of $S$. caprae M23864:W1 strain could not clarify the complete sequences of biofilm-associated genes encoding Embp/EbphA and ClfB-like genes since they might contain repeat sequences. In the case of the draft sequence, assembly is incomplete; there may be errors in the sequences; and annotation is incomplete. Determined complete whole-genome sequences of three methicillin-resistant $S$. caprae strains are shown in Fig. 1. The strains of $S$. caprae JMUB145, JMUB590, and JMUB898 contained one single circular chromosomes, and one, five, and seven plasmids, respectively. The respective chromosome sizes of $S$. caprae JMUB145, JMUB590, and JMUB898 were 2,618,380, 2,629,173, and 2,598,513 bp, with almost identical $\mathrm{G}+\mathrm{C}$ content (33.6\%). A total of $2,489,2,510$, and 2,476 protein-CDSs were annotated on the chromosomes of $S$. caprae JMUB145, JMUB590, and JMUB898, respectively. S. caprae JMUB145, JMUB590, 


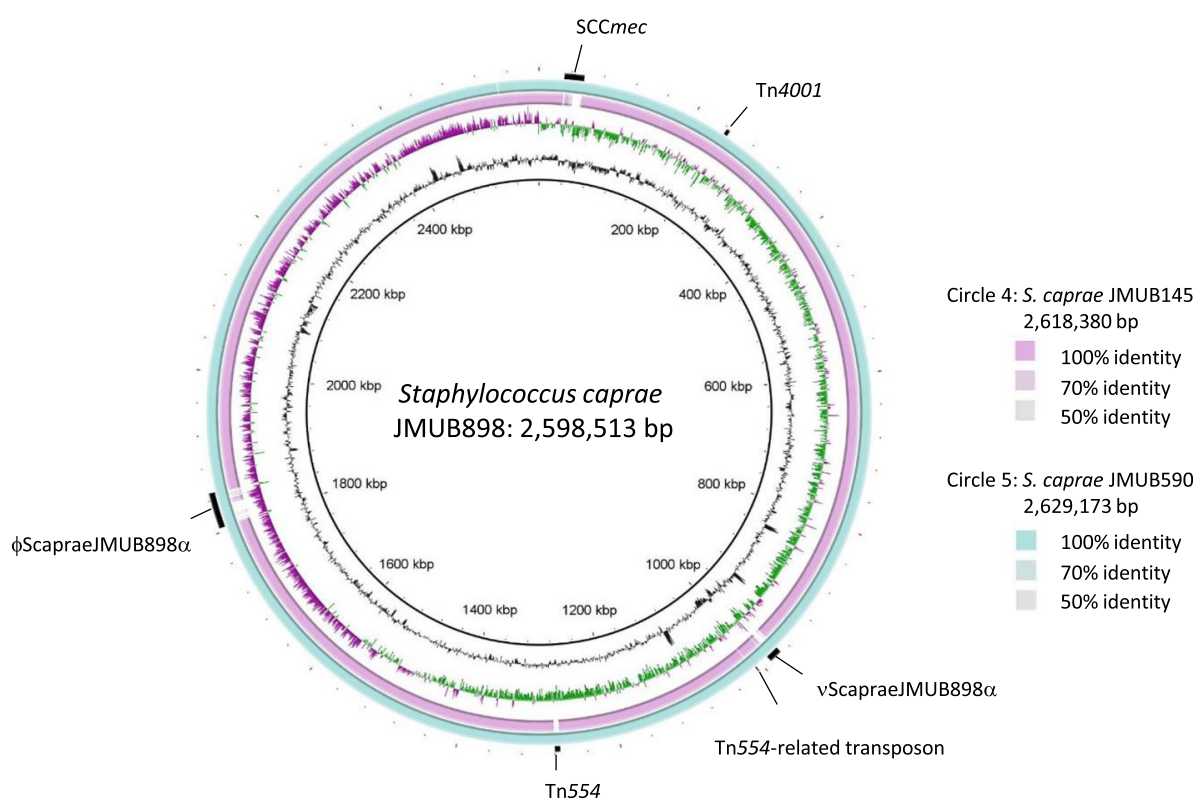

Fig. 1 Circular representation of the genome comparison of three Staphylococcus caprae strains. Circle 1 (innermost circle) and circle 7 (outermost circle) indicate the distances from the putative origin of replication of the S. caprae JMUB898 chromosome. Circles 2 and 3 designate the GC content (black) and GC skew (green, plus strand; purple, minus strand). Circle 4 shows nucleotide identities between S. caprae JMUB145 and JMUB898 chromosomes calculated by blastn (light blue). Circle 5 represents nucleotide identities between S. caprae JMUB590 and JMUB898 chromosomes. Circle 6 shows prophages, genomic islands, and transposons (black). The S. caprae genomes are compared and visualized by BLAST Ring Image Generator v0.95 [19]

and JMUB898 strains were also found to contain six, five, and five rRNA-encoding gene (rDNA) clusters, as well as 59, 59, and 58 tRNA genes, respectively.

Figure 1 shows the blastn identities of CDSs among individual genomes of $S$. caprae JMUB898, JMUB145, and JMUB590 chromosomes, with JMUB898 as the central reference chromosomal sequence [19]. Most of the differences between $S$. caprae genomes were found on genomic islands including SCCmec, prophages, and transposons (Fig. 1). JMUB145 carried a type V SCCmec element. The entire structure of SCCmec in the JMUB145 genome was almost identical with that of $S$. aureus JCSC5952, which was isolated from children with impetigo in Japan in 2002 (Fig. 2) [20]. The SCCmec of JMUB145 also showed high similarity with that of $S$. pseudointermedius 06-3228, which was isolated from a $\operatorname{dog}$ [21]. The SCCmec of JMUB145 possessed two $c \mathrm{crC}$ genes: $c c r C 1$ allele $2(c c r C 2)$ and $c c r C 1$ allele 8 ( $c r C 8)$. Both JMUB590 and JMUB898 carried type IVa SCCmec elements, which are closely related to type IVa SCCmec of the S. aureus USA300 TCH1516 strain (Fig. 2) [22].

\section{Phylogenetic relationship among S. epidermidis, S. capitis and S. caprae}

To date, the genus Staphylococcus has been classified into more than 47 species and 23 subspecies, comprising 15 cluster groups, based on a phylogenetic analysis performed using DNA sequence data from multiple loci, such as the 16S rRNA gene and dnaJ, rpoB, and tuf gene fragments [7, 15]. S. caprae, together with S. epidermidis, S. capitis subsp. capitis, S. capitis subsp. urealyticus, and $S$. saccharolyticus, belongs to the epidermidis cluster group [7, 15]. Species of the epidermidis cluster group showed oxidase-negative, novobiocin-susceptible, and coagulase-negative phenotypes. To confirm the phylogeny of the genus Staphylococcus, we constructed a genome-wide phylogenetic SNP tree using three $S$. caprae chromosome sequences determined in this study and 80 complete genome sequences of 24 Staphylococcus species available on GenBank (Additional file 1 Table S1). We also included two S. caprae draft genome sequences, which are also available on GenBank, into the analysis. The phylogenetic analysis confirmed that S. epidermidis, S. capitis, and S. caprae strains of the epidermidis cluster group fell into a single clade (Fig. 3). Based on the SNP tree, the epidermidis cluster group is most closely related to $S$. haemolyticus strains (Fig. 3).

To elucidate the genome structure of the epidermidis cluster group, we compared the entire chromosome sequences among S. epidermidis, S. capitis, and S. caprae strains. The chromosome sequence of $S$. caprae JMUB898 was compared with those of S. caprae JMUB145 and JMUB590 by dot plot analysis (Fig. 4). Moreover, the $S$. caprae JMUB898 chromosome sequence was also compared with the complete genome sequences or complete chromosome sequences of seven 


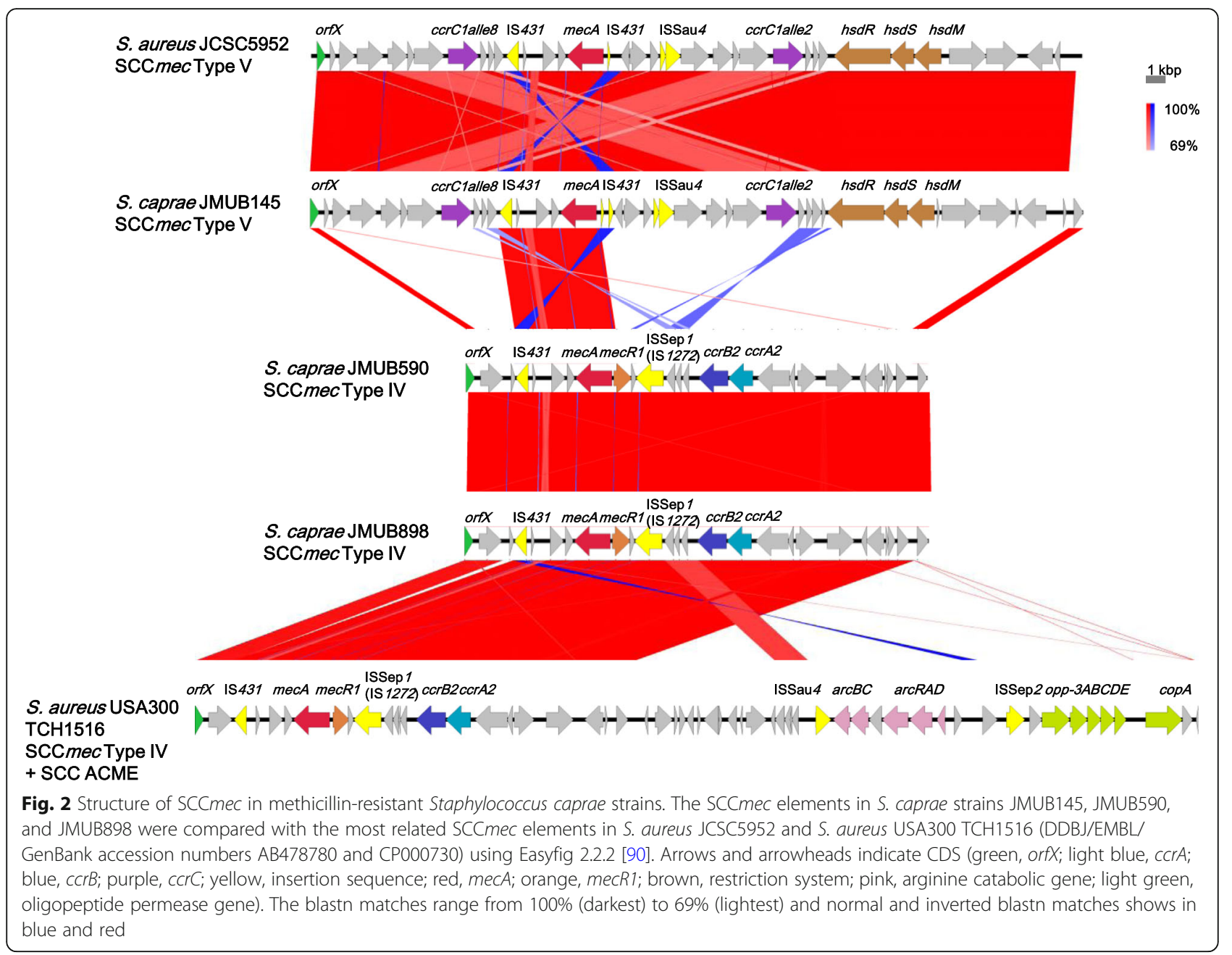

S. epidermidis and three S. capitis strains. Dot plot analysis revealed that genome structures were relatively conserved among S. caprae and S. capitis strains (Fig. 4). However, as compared with the S. caprae JMUB898 chromosome, three of seven S. epidermidis chromosomes (ATCC12228, PM221 and BPH0622) were inverted around oriC. The $S$. aureus chromosome was also inverted around oriC when chromosome sequences were compared between S. caprae JMUB898 and S. aureus N315 (Fig. 4).

Identification of species-specific genes in S. epidermidis, $S$. capitis and S. caprae and conserved genes among the epidermidis cluster group

In order to uncover the genetic diversity of the epidermidis cluster group, we first determined the core/pan-genome of each species to estimate the number of shared genes between every S. epidermidis, S. capitis, and S. caprae strain. Although more than 400 genome sequences of the epidermidis cluster group are available on GenBank, including draft genome sequences, we focused on the complete genome-sequenced strains. Complete genome sequences are considered to be more reliable and allow identification of precise strain-specific genes on each chromosome. In this core/pan-genome analysis, genes harbored on genomic islands, prophages, $\mathrm{SCCmec}$, and transposons were separated from the category of conserved genes in each species. There were a total of 1,945 conserved genes identified among all S. epidermidis strains (Fig. 5 and Additional file 2 TableS2). Similar to S. epidermidis, 2,064 and 2,313 conserved genes were shared between every $S$. capitis and $S$. caprae strain, respectively. The conserved genes showed high sequence similarity among the three species. More than $95 \%$ of conserved genes displayed $>95 \%$ sequence identities by interspecies comparison (Additional file 2 TableS2).

Next, we sought to identify both conserved and species-specific gene sets of the epidermidis cluster group using the conserved gene sets of each species. As shown in Fig. 5, 1,719 CDSs were conserved among the three species, while 141, 59, and 263 species-specific genes were identified in S. epidermidis, S. capitis, and $S$. caprae, respectively. We also found that 21,265 , and 64 


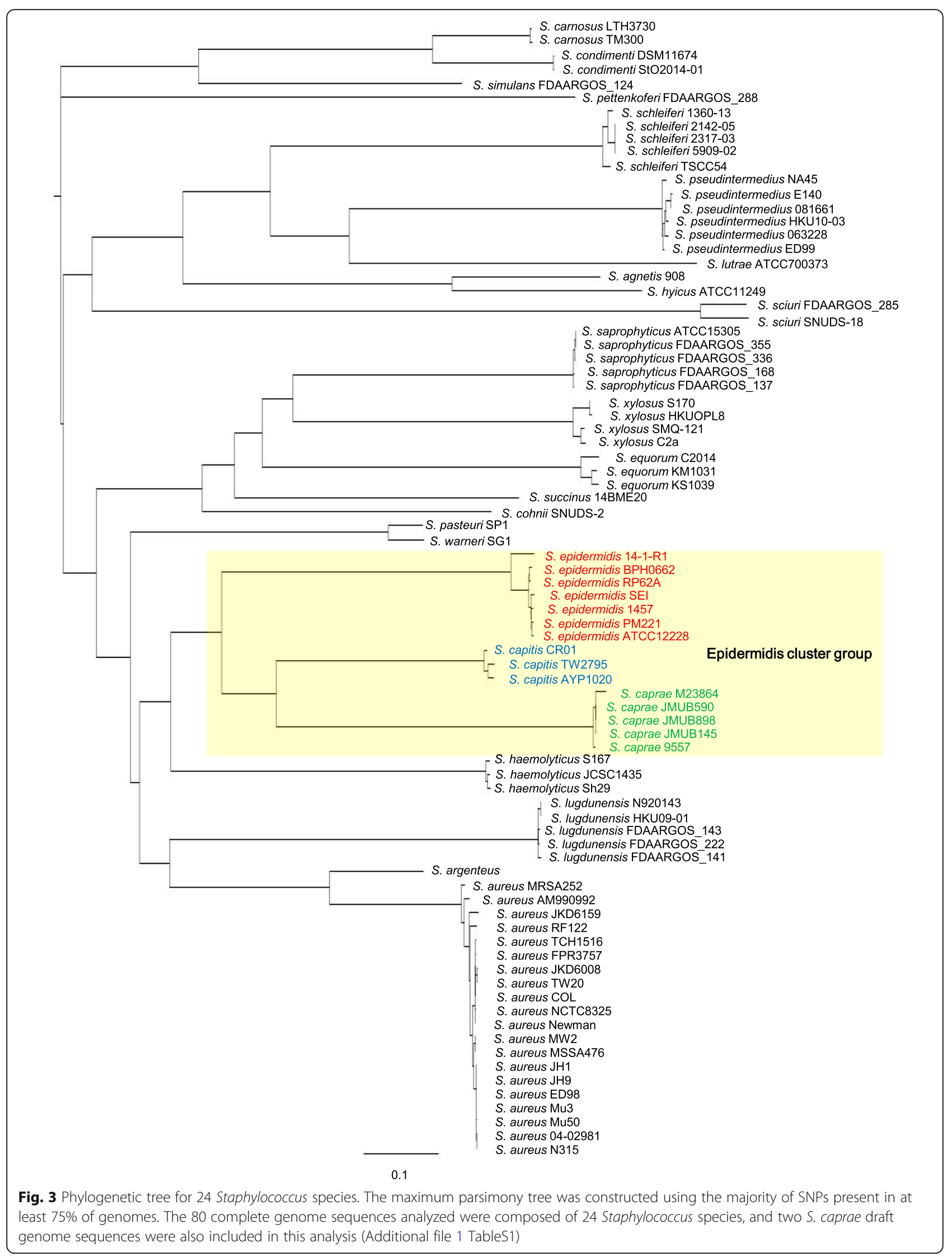




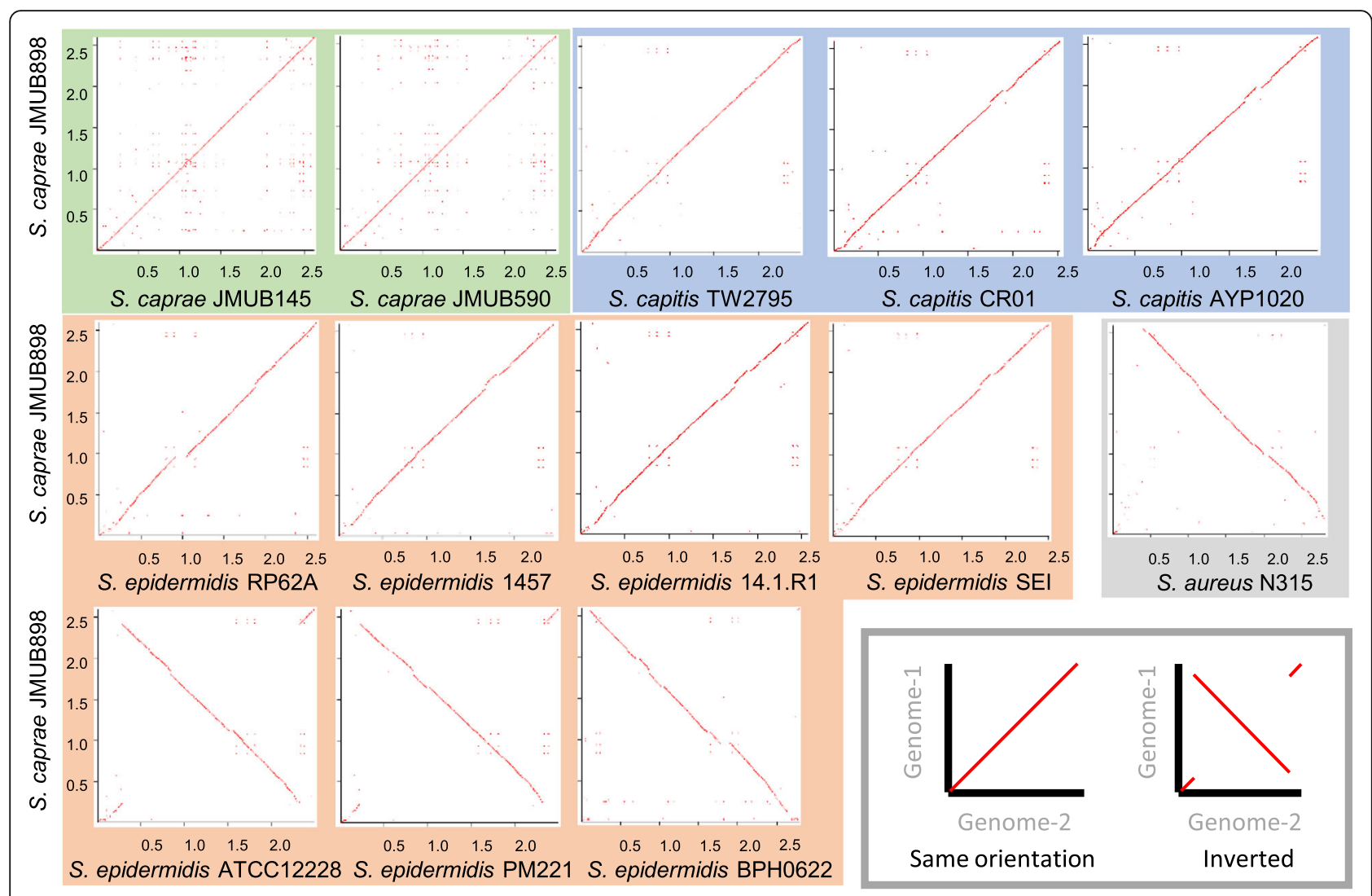

Fig. 4 Dot plots of Staphylococcus epidermidis, S. capitis, and S. caprae chromosomes. The S. caprae JMUB898 chromosome was compared with those of two S. caprae strains (green), three S. capitis strains (blue), seven S. epidermidis strains (orange), and one S. aureus strain (gray) by in silico Molecular Cloning Genomics Edition ver. 6.0.11D. A dot is plotted at every co-ordinates having similarity between two chromosomes

genes were shared between species when comparing $S$. epidermidis vs $S$. capitis, $S$. capitis vs $S$. caprae, and $S$. caprae vs S. epidermidis, respectively (Fig. 5d).

To analyze the genome robustness or plasticity of the epidermidis cluster group, the gene sets specific to each species, shared between two species, and conserved among all three species were mapped on S. epidermidis RP62a, S. capitis TW2795, and S. caprae JMUB898 chromosomes (Fig. 6). The gene synteny was found to be well retained in the chromosome of the epidermidis cluster group. However, the chromosomal regions where some species-specific genes were clustered in each species seem to be the remnants of genomic islands.

The downstream regions of SCCmec elements also were not conserved among the three species. Our analysis revealed that the species-specific genes of $S$. capitis and $S$. caprae were typically mapped to the downstream of SCC elements, similar to that of $S$. aureus, S. epidermidis, and $S$. haemolyticus genomes [23] (Fig. 6). Some remnants of prophages or genomic islands were also found (Fig. 6). These species-specific genomic regions are considered likely to contribute to the evolution and differentiation of Staphylococcus species differentiation [23].
Although the downstream regions of the SCCmec elements were divergent among species, we found that the type V SCCmec identified in the S. caprae JMUB145 genome was closely related to those of $S$. aureus JCSC5952 and S. pseudointermidius 06-3228 (Fig. 2) [20, 21], while type IVa SCCmec of S. caprae JMUB590 and JMUB898 was closely related to that of the $S$. aureus USA300 TCH1516 strain (Fig. 2) [22]. The SCCmec of methicillin-resistant $S$. caprae has rarely been analyzed. Previous studies showed that $S$. caprae stains carried a variety of mec gene complexes, for example, one $S$. caprae strain isolated from pig was reported to carry class A mec and type I $c c r$ [24, 25], and in S. epidermidis and $S$. capitis strains, type I-V SCCmec elements (originally identified in MRSA) were identified by PCR-based methods [7]. It might be interpreted as the results of co-evolution and interspecies exchange of the SCCmec elements over long-term evolution.

\section{Genes conserved across three species}

Our analysis identified 1,719 conserved CDSs among $S$. epidermidis, S. capitis, and S. caprae. Most of the conserved genes are involved in fundamental biological 


\section{A s. epidermidis}

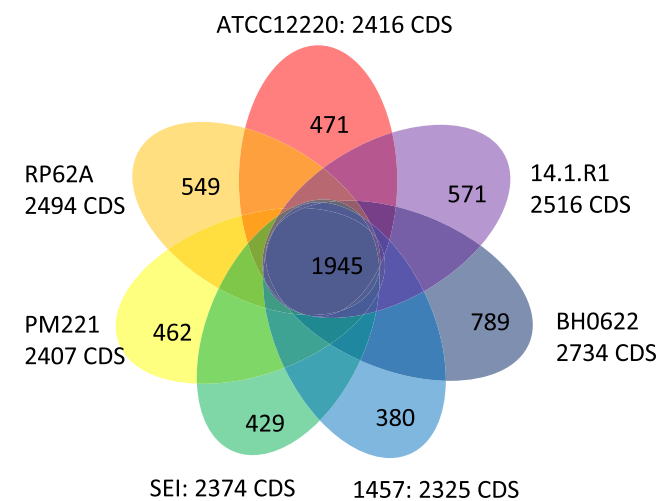

\section{C s. caprae}

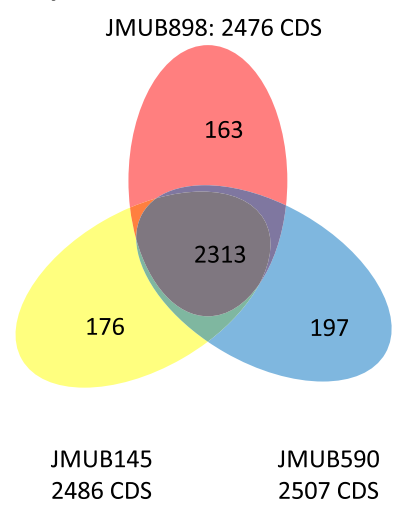

\section{B s. capitis}

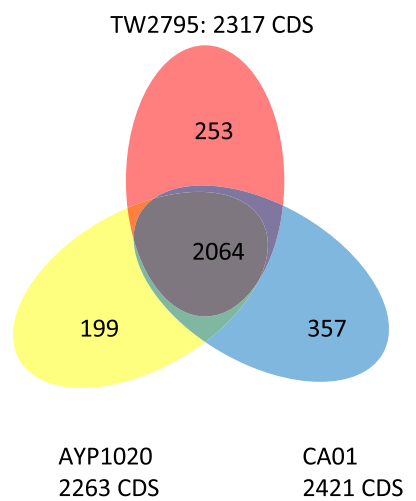

D Epidermidis cluster group

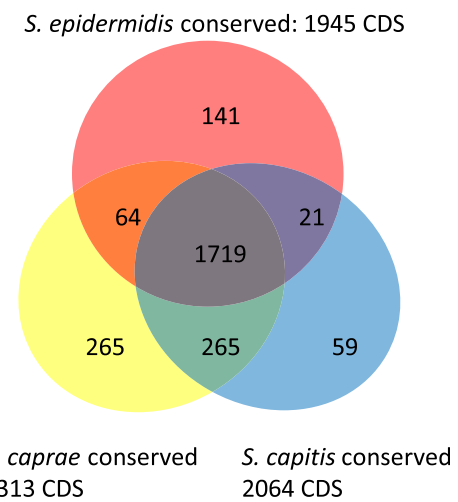

Fig. 5 Venn diagram displaying the comparative gene orthology among a Staphylococcus epidermidis, b S. capitis, c S. caprae, and $\mathbf{d}$ the epidermidis cluster group strains. The numbers indicate the unique genes in each strain or the shared genes between groups of strains, satisfying the criteria of more than $50 \%$ amino acid identity on $50 \%$ of the total length of a protein

processes. Compared with the highly virulent $S$. aureus, the three species possessed fewer known and putative virulence factors. Well-known virulence factors of $S$. aureus such as coagulase, protein A, leukocidins, $\alpha$-toxin, and staphylococcal enterotoxins were missing from these genomes. Nevertheless, the three species shared virulence factors involved in biofilm formation and protection against the innate immune system. Furthermore, teichoic acid biosynthesis genes (tagAHGBXD) encoding wall teichoic acid (WTA) were conserved among the three species. This gene cluster confers positive charge to bacterial cells, thereby mediating primary adherence to polystyrene surfaces as well as host organisms to initiate biofilm formation [7]. The dltABCD genes were also conserved among the three species. $\operatorname{dlt} A B C D$ genes function as the modification system for WTA by incorporating D-alanine into WTA [26]. Our genome analysis also confirmed that all analyzed genomes from the three species (S. epidermidis, S. capitis, and S. caprae) shared poly- $\gamma$-DL-glutamic acid (PGA) genes. The PGA capsule is another Staphylococcus extracellular virulence factor found in S. epidermidis, which facilitates bacterial growth and survival in the human host [27]. Kocinaova et al. described that all tested S. epidermidis strains and the reference strains of the epidermidis cluster group, including S. capitis subsp. capitis, S. capitis subsp. ureolyticus, and S. caprae, produced PGA, and carried $c a p B$ and $c a p D$ genes [27]. The other extracellular proteins such as secreted thermonuclease [28] and Clp protease [29] involved in biofilm formation were also found to be conserved among the three species.

The three $S$. caprae strains carried two phenol soluble moduline (PSM) gene clusters, PSM $\beta$ and PSM $\alpha / \mathrm{PSM} \delta$. The former was located upstream of Arginine-tRNA and was conserved among the Staphylococcus species, including S. epidermidis, S. capitis, and S. caprae. The number of genes of a PSM $\beta$ cluster has been shown to vary from two to six [17]. Consistent with this previous report [17], the PSM $\beta$ cluster of the three S. caprae strains contained five genes, while that of S. epidermidis RP62a and S. capitis TW2795 consisted of four genes. The PSM $\alpha /$ PSM $\delta$ cluster of $S$. caprae was located upstream of the NADH dehydrogenase gene and contained single copies of PSM $\alpha$ and PSM $\delta$. PSM $\alpha$ and PSM $\delta$ were conserved in S. epidermidis RP62a and S. capitis TW2795 strains. 

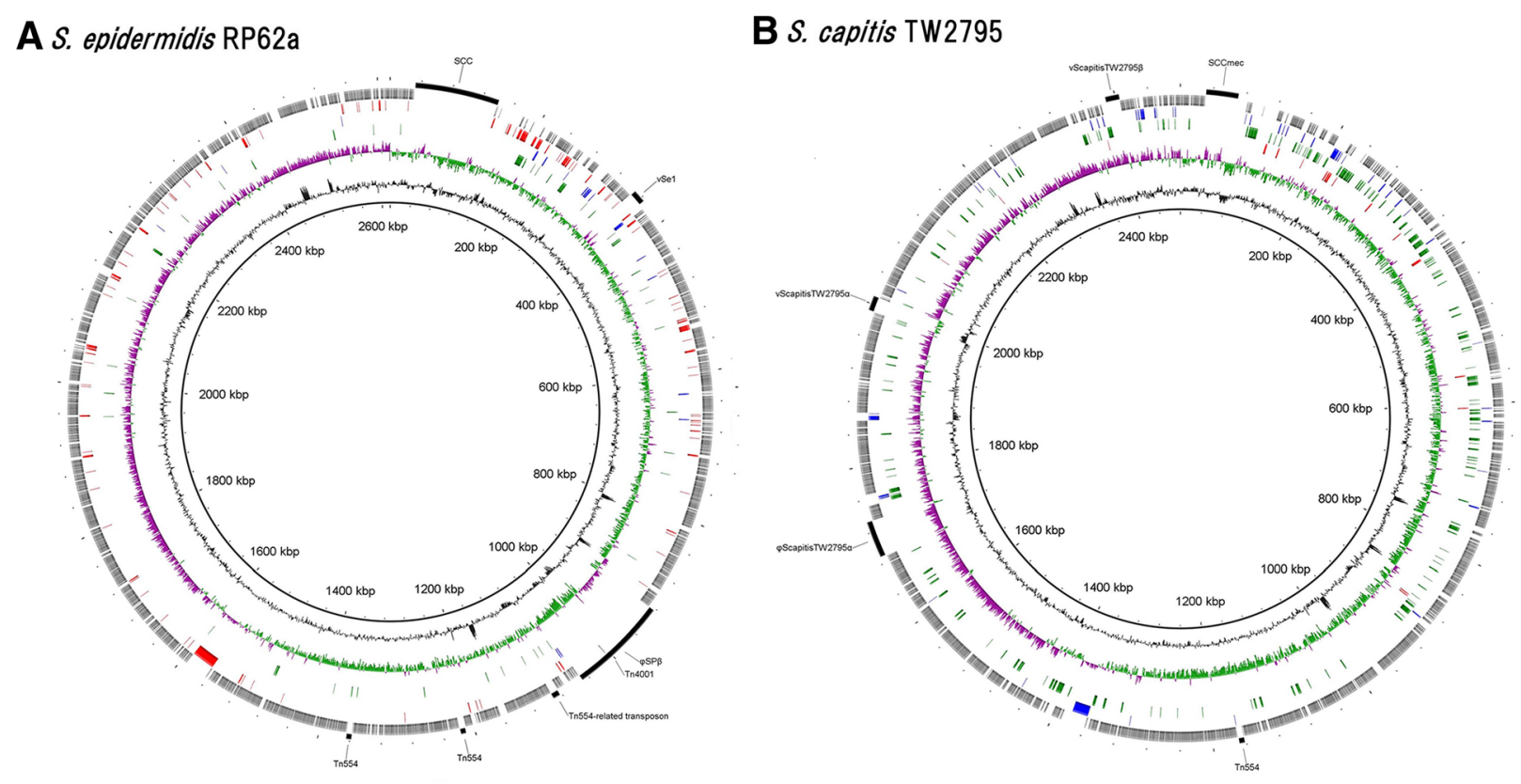

\section{C s. caprae JMUB898}

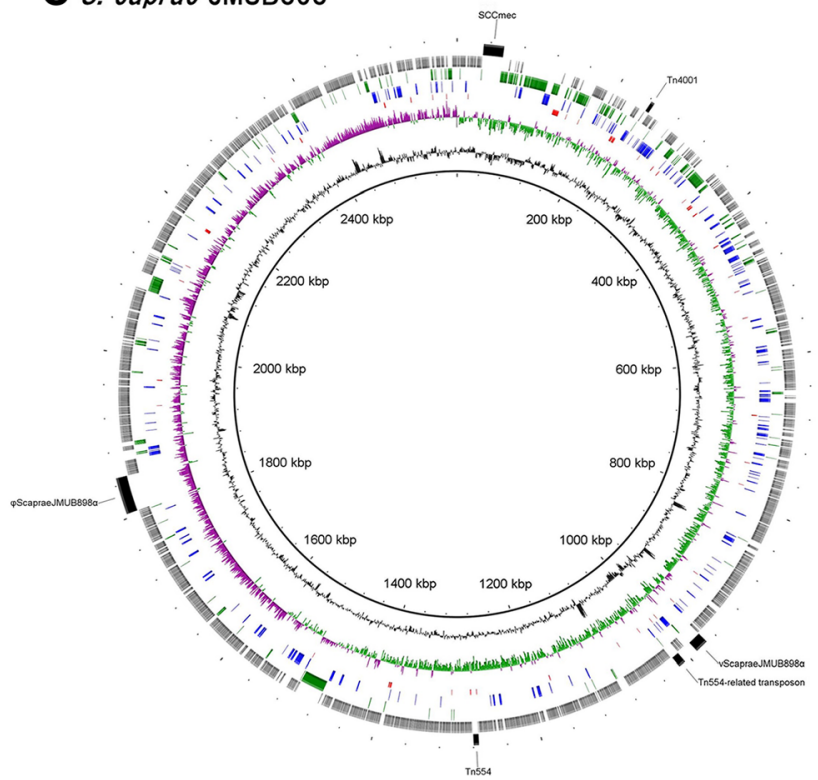

Fig. 6 Distribution of core and unique gene sets on the chromosomes of Staphylococcus epidermidis RP62a, S. capitis TW2795, and S. caprae JMUB898. Core and unique gene sets are plotted on the chromosomes of (A) S. epidermidis RP62a, (from the periphery toward the center) Circle 1, genomic island; Circle 2, Epidermidis cluster group-conserved genes; Circle 3, S. epidermidis-conserved genes; Circle 4, S. epidermidis-S. capitis-shared gene; Circle 5, S. epidermidis-S. caprae-shared gene; Circle 6, GC skew; Circle 7, GC count; Circle 8, nucleotide position (B) S. capitis TW2795, Circle 1, genomic island; Circle 2, Epidermidis cluster group-conserved genes; Circle 3, S. capitis-conserved genes; Circle 4, S. capitis-S. caprae-shared gene; Circle 5, S. capitis-S. epidermidis-shared gene; Circle 6, GC skew; Circle 7, GC count; Circle 8, nucleotide position, and (C) S. caprae JMUB898, Circle 1, genomic island; Circle 2, Epidermidis cluster group-conserved genes; Circle 3, S. caprae-conserved genes; Circle 4, S. caprae-S. capitis-shared gene; Circle 5, S. caprae-S. epidermidis-shared gene; Circle 6, GC skew; Circle 7, GC count; Circle 8, nucleotide position, by BLAST Ring Image Generator v0.95 [19]

\section{Divergent interspecies evolution of cell surface extracellular proteins}

Cell surface extracellular proteins mediate bacterial adherence to abiotic surfaces and host tissues as well as intercellular adhesion during biofilm formation [7]. By analyzing the conserved genes among the three species, S. epidermidis, S. capitis, and S. caprae, we found that most cell surface proteins showed substantially lower sequence identities between species compared with the other conserved proteins. The average of amino acid 
identities for total conserved genes were 80.4, 90.9, and $84.8 \%$ among $S$. epidermidis RP62a vs $S$. capitis TW2795, S. capitis TW2795 vs S. caprae JMUB898, and S. caprae JMUB898 vs $S$. epidermidis RP62a, respectively. In contrast, the identities for cell surface proteins were less than $50 \%$. Since we set a cutoff value of $50 \%$ for amino acid identity in this analysis, proteins with amino acid identities of less than $50 \%$ must be categorized as species-specific proteins. However, even though most cell surface proteins had less than 50\% identities among the three species, they could be considered as homologues of each other, because they were judged to share the same ancestors or origin by analyzing gene structure, location on the genome, and functional motifs. For example, S. capitis and S. caprae carried SesC-like proteins. The amino acid sequence identities of SesC/ SesC-like proteins were $45.0 \%$ between $S$. epidermidis RP62a and S. capitis TW2795 and 46.1\% between S. epidermidis RP62a and S. caprae JMUB898. The SesC-like proteins are postulated to have a similar function as $\mathrm{SesC}$ in $S$. epidermidis because SesC-like proteins in $S$. capitis and $S$. caprae contain the LPXTG motif, as does $\mathrm{SesC}$ in S. epidermidis. Moreover, the genome loci of the genes were considered to be the same since the upstream region of every $\operatorname{ses} C$ in these three species contained a gene encoding an organic hydroperoxide resistance-like protein. Therefore, SesC-like proteins in $S$. capitis and $S$. caprae might function as host cell factors and/or abiotic surface-binding proteins owing to the fact that SesC in $S$. epidermidis is one of the fibrinogen-binding proteins containing a wall-anchoring LPXTG motif that mediates biofilm formation [30] although the amino acid identities of the three proteins were shown to be less than $50 \%$. These lower identities seemed to reflect their divergent interspecies evolution.

In this study, we also identified the cell surface proteins involved in adhesion and biofilm formation and created a heat map of these proteins based on their amino acid identities (Fig. 7). We found that 17 of the 26 cell surface proteins were well conserved in the three species. Eleven cell-wall-anchored proteins, SesA-I and SdrFG, which contained an N-terminal secretion signal sequence and wall-anchoring LPXTG motif, were predicted from the $S$. epidermidis RP62a genome sequence [31]. These proteins are involved in bacterial attachment to host tissue or cells and biofilm formation. Although 5 (sesABCEH) of the 11 genes encoding the cell wall-anchored proteins were identified at the similar genome locus tags of the three species, there were few interspecies similarities. The amino acid identities of SesA, SesB, SesC, SesE, and SesG between S. epidermidis RP62A and $S$. capitis TW2795 were 53.2, 75.0, 45.0, 34.6, and 58.0\%, respectively, while those between S. epidermidis RP62A and S. caprae JMUB898 were 58.3, 75.5,

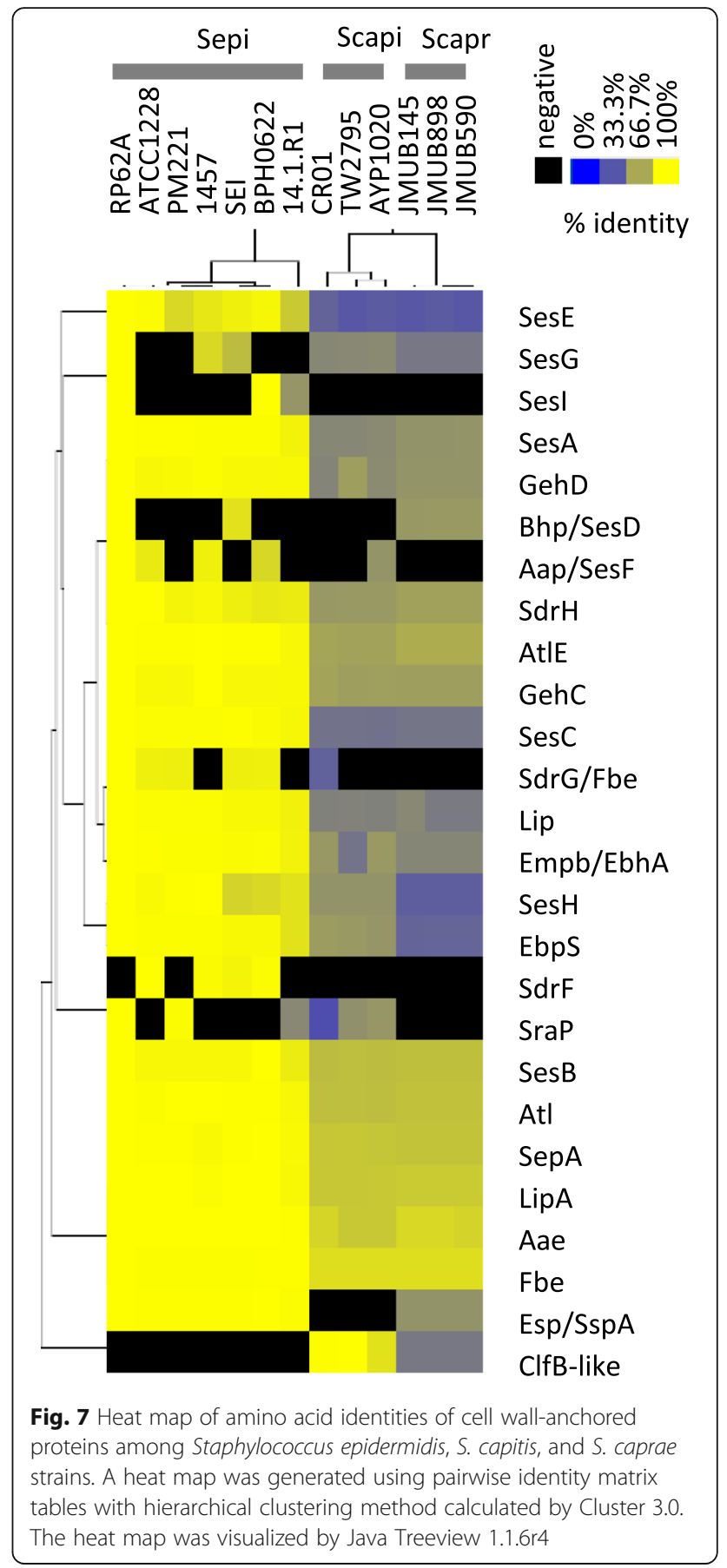

46.1, 35.9, and 37.2\%, respectively. In addition to SesA-I and SdrFG, S. epidermidis strains carry an extracellular matrix-binding protein Embp/EbhA that is similar to Ebh identified in $S$. aureus [32, 33]. S. capitis and $S$. caprae also carry Embp/EbhA-like proteins with the amino acid identities of $\sim 60.3 \%$ compared with those of S. epidermidis.

S. epidermidis carries three multifunctional autolysin/ adhesins, AtlE, Atl, and Aae, which mediate both cell 
lysis and attachment to materials including host tissue or cells, abiotic surfaces, and extracellular DNA [27, 34]. Similar to other cell surface proteins containing an LPXTG motif, these proteins are conserved among the three species, but the amino acid identities were less than the average amino acid identities of conserved proteins. The most analyzed staphylococcus autolysin is AtlE in S. epidermidis, and the atlE gene disseminates among staphylococcal species. AtlE homologues, such as Atl in S. aureus, Atl $\mathrm{wm}_{\mathrm{wm}}$ in S. warneri, AtlC in S. caprae, Aas in S. saprophyticus, and AtlL in S. lugdunensis, have been reported as fibronectin-binding proteins involving in biofilm formation [35-37].

Most organisms colonizing human skin possess lipolytic activity to hydrolyze lipids found on the surface of human skin [38]. Other than cell wall-anchored proteins, extracellular lipases, GehCD, Lip, and LipA, which mediate bacterial colonization on human and animal skins, were conserved in S. epidermidis, S. capitis, and $S$. caprae with high interspecies diversity [39, 40]. Every strain in the epidermidis cluster group also possesses an extracellular metalloprotease with elastase activity, such as SepA (SE2219) that plays a role in conferring resistance to the antimicrobial peptide dermicidin [41].

The elastin-binding protein (ebpS) or ebpS-like genes were also found to be conserved among $S$. epidermidis, $S$. capitis, and S. caprae strains. Similar to extracellular lipases, EbpS also showed high diversity among the three species. Our analysis categorized S. epidermidis EbpS as a different protein from the EbpS of S. capitis and S. caprae since the amino acid identity of EbpS proteins between $S$. epidermidis and S. caprae was less than $39.9 \%$, and the length of the homologous region between EbpS of S. epidermidis and S. capitis was less than $50 \%$ of the entire region. As reported in S. aureus, EbpS was first identified as an adhesin for extracellular matrix elastin of host cell tissue [42]. However, EbpS in S. aureus shows relatively weak binding potential to elastin [43]. The adherence of some $S$. aureus strains to immobilized elastin is mediated by fibronectin-binding proteins FnBPA and FnBPB, but not by EbpS, and the inactivation of ebpS in $S$. aureus strains has only a minimal effect on the binding of $S$. aureus to elastin peptide [43]. Regardless, it was recently reported that EbpS regulates bacterial growth rate in liquid culture and promotes biofilm maturation in a zinc concentration-dependent manner [44]. Therefore, EbpS and EbpS-like proteins of the epidermidis cluster group might play a role in biofilm maturation.

\section{Genes shared by S. capitis and S. caprae but not by S. epidermidis}

Based on the phylogenetic analysis, S. capitis is more closely related to $S$. caprae than $S$. epidermidis. Therefore, a larger set of shared genes could be identified between $S$. capitis and S. caprae than when comparing $S$. epidermidis with $S$. capitis or $S$. epidermidis with $S$. caprae (Fig. 5 and Additional file 2 TableS2). Four major biofilm formation-related factors were shared by S. capitis and $S$. caprae. These include polysaccharide intracellular adhesin (PIA), elastin-binding protein (EbpS), SesC-like proteins, and SdrH-like proteins. Since EbpS, $\mathrm{SesC}$, and SdrH of S. capitis and S. caprae (EbpS-like, SesC-like, and SdrH-like proteins) showed lower similarities (add number \%) to those of S. epidermidis, they were categorized as shared by $S$. capitis and S. caprae.

PIA, also known as poly- $N$-acetylglucosamine, mediates biofilm formation and plays an important role in immune evasion [45-47]. PIA production is regulated by the ica operon $(i c a A D B C)[45,48]$, and the ica locus has been identified in many staphylococcal species including S. aureus, S. capitis, and S. caprae $[49,50]$. We found that all $S$. capitis and $S$. caprae strains analyzed in this study possessed the ica operon. However, only three $S$. epidermidis strains (RP62a, 1457, and BH0622) carried the ica operon. This is in concordance with a previous study where a number of ica negative clinical isolates of S. epidermidis were reported [51].

SesG is one of the cell surface-anchored proteins identified in the S. epidermidis RP62a genome. Although four of the seven S. epidermidis strains lack the ses $G$ gene, every $S$. capitis and $S$. caprae strain analyzed in this study carried the ses $G$ gene, which had amino acid identities of $53.2-54.6 \%$ (S. epidermidis RP62a vs S. capitis) and $47.2-53.2 \%$ (S. epidermidis RP62a vs S. caprae).

S. capitis and S. caprae also shared the same mannitol metabolic pathways. Mannitol utilization has been adapted for species classification among CoNS [52]. Our genome analysis confirmed that mannitol acquisition and utilization pathways are conserved in mannitol-positive species such as $S$. capitis and $S$. caprae, while mannitol-negative $S$. epidermidis species lacks this system. Arginase, which catalyzes the fifth and final steps in the urea cycle, resulting in the conversion of L-arginine into L-ornithine and urea, was conserved in S. capitis and S. caprae but not in S. epidermidis. It is interesting that urease genes were conserved in all three species, yet urease activity, being one of the key phenotypes for classification of CoNS, was shown to be negative in S. capitis subsp. capitis [52]. S. capitis and $S$. caprae also shared staphyloxanthin biosynthesis genes crtOPQMN. These genes regulate the production of orange carotenoid, conferring the characteristic golden-yellow color of colonies, which aids in distinguishing S. aureus from S. epidermidis [53]. A clumping factor B-like protein gene, located at the identical locus downstream of the $\operatorname{arcR}$ gene was identified in S. capitis and S. caprae genomes but not in the $S$. epidermidis genome. 
Genes shared by S. epidermidis and S. capitis but not by S. caprae

S. epidermidis and S. capitis shared 21 genes (Fig. 5), among which are the accessory Sec systems. The canonical Sec system, which translocates the majority of proteins across the cytoplasmic membrane, is present in all bacteria including staphylococcal species. In addition to the canonical Sec system, accessory Sec systems were found in $S$. epidermidis and $S$. capitis but not in $S$. caprae. The accessory Sec systems are conserved in staphylococci and streptococci, facilitating the transportation of serine-rich repeat glycoproteins [54, 55]. In $S$. aureus, the accessory Sec system secretes the serine-rich glycoprotein SraP, which mediates staphylococcal binding on human platelets [54]. S. capitis possesses a SraP homologue (JMUB0001_172). Although the SraP homologue was not conserved in all S. epidermidis strains, we identified it in S. epidermidis RP62a, PM221, and 14.1.R1 strains. This finding indicated that the additional Sec system might contribute to glycoprotein translocation.

Our genome comparison analysis showed that 5 of the 11 cell wall-anchored proteins identified in the $S$. epidermidis RP62a genome were conserved among S. epidermidis, S. capitis, and S. caprae (Fig. 7 and Additional file 2 TableS2). Another two genes, sesF and $s d r G$, were identified only in some $S$. epidermidis and $S$. capitis strains but not in $S$. caprae. The sesF gene, encoding the accumulation-associated protein Aap, had been identified as an essential protein for biofilm accumulation on glass or polystyrene surfaces in certain S. epidermidis strains $[56,57]$. The giant extracellular protein mediates biofilm formation and accumulation via fibronectin-binding and intercellular adhesion abilities [58, 59]. Four of the seven genome-sequenced $S$. epidermidis strains and one of the three $S$. capitis strains carried the aap gene on their chromosomes. In contrast, five of the seven genome-sequenced $S$. epidermidis strains carried the sdrG/fbe gene, while 1457 and 14.1.R1 lacked this gene. S. capitis CR01 also had the SdrG/Fbe-like protein with an amino acid identity of $38.4 \%$ between RP62a and CR01. SdrG, one of the three SD repeats-containing serine asparagine-rich (Sdr) proteins identified in S. epidermidis RP62a (also known as fibrinogen-binding protein [Fbe]), was suggested to promote device-related infection due to the observation of that an $s d r G / f b e$ deletion mutant was attenuated in an intravascular catheter-associated rat infection model [60-62].

Genes shared by S. epidermidis and S. caprae but not by S. capitis

We found that $S$. epidermidis shared 64 genes with $S$. caprae strains (Fig. 5). Every sequenced S. epidermidis and $S$. caprae strain carried serine V8 protease GluSE, also known as Esp/SspA (SE1543) [63-65]. When S. epidermidis and $S$. aureus co-exist in an organism, Esp produced by commensal $S$. epidermidis strains inhibits $S$. aureus biofilm formation and subsequently its colonization in the anterior nares [66]. The esp gene was not found in the three sequenced $S$. capitis strains.

All sequenced $S$. epidermidis and $S$. caprae strains also carried the arginine synthesis pathway genes $\operatorname{argJBCD}$. L-Arginine is required for the growth of most Staphylococcus species, including $S$. aureus, $S$. epidermidis, and $S$. capitis [67]. The presence of argJBCD genes in S. epidermidis and $S$. caprae is consistent with a previous study where the mutants not requiring L-arginine were generated by in vitro selection from $S$. epidermidis strains but not from S. capitis strains [67]. This implies that S. epidermidis strains might have the arginine biosynthesis enzymes, but the enzymes were not expressed in the wild-type strains [67].

\section{Genes carried by S. epidermidis but not by S. capitis and S. caprae}

Each of the seven S. epidermidis strains tested carried 380-789 strain-specific genes. The conserved gene analysis identified 141 genes that were conserved in all $S$. epidermidis strains but not in $S$. capitis or $S$. caprae. Most of these $S$. epidermidis-specific genes encode virulence factors that have been known to mediate biofilm formation or be involved in the central metabolic pathways.

The cell wall-anchored protein SdrF was identified only in four of seven $S$. epidermidis strains. The full-length $s d r F$ gene, which encodes a type I collagen-binding protein, was identified in SEI, 1457, and BH0622 genomes. Nevertheless, truncated $s d r F$ genes were found in S. epidermidis RP62a, PM221, and 14.1R1. S. capitis AYP1020 also carries the truncated SdrF homologue with $73.3 \%$ amino acid identity, but the $S$. capitis $s d r F$ gene was fragmented by a frameshift mutation.

The genome comparison revealed that S. epidermidis has a specific central metabolism pathway that does not exist in the genomes of $S$. capitis and S. caprae. S. epidermidis possesses the glycerol dehydrogenase gene gldA, which mediates glycerol metabolism. A previous study showed that $S$. epidermidis could ferment glycerol into succinate, and the resulting succinate could in turn inhibit the growth of another skin colonizer P. acnes in vitro and in vivo [68]. Moreover, S. epidermidis strains, but not $S$. capitis and $S$. caprae strains, carried fumarate reductase-mediating succinate fermentation and accumulation [69]. S. epidermidis also carried biosynthesis genes for biotin, which is a cofactor of acetyl-CoA carboxylase involved in fatty acid metabolism. 
Genes carried by S. capitis but not by S. epidermidis and S. caprae

Each of the three S. capitis strains tested carried 199357 strain-specific genes, in which 59 were identified by our analysis to be $S$. capitis specific. Many species of Gram-positive bacteria, including staphylococci, produce lantibiotics and small cationic antimicrobial peptides to provide antimicrobial activities in facilitating niche compensation [70]. Some CoNS strains produce unique lantibiotics such as epidermin (from S. epidermidis) and gallidermin (from S. Gallinarum) [71-73]. Kumar et al. reported an identification of an $S$. capitis strain TE8 that carried both epidermin and gallidermin gene loci [17]. In our analysis, all three $S$. capitis strains tested carried lantibiotics genes on their chromosomes, but they were similar to that of S. aureus RF122 with an amino acid identity of $47 \%$ [74].

All three $S$. capitis strains and S. epidermidis RP62A, PM221, and 14.1.R1 carried serine-rich adhesin for platelet (SraP) homologues. SraP homologues have been widely identified among staphylococci including $S$. aureus and S. gordonii [75]. SraP mediates bacterial binding to platelets, whereby the binding is considered the key step during infective endocarditis $[75,76]$.

\section{Genes carried by S. caprae but not by $S$. epidermidis and S. capitis}

Our genome analysis identified a total of 265 genes that were carried by $S$. caprae but not by any of $S$. epidermidis and S. capitis strains, of which 163-197 were carried by five individual strains of $S$. caprae tested. Among those, biofilm-associated protein (Bap), capsular polysaccharide, and type VII secretion factor recognized as virulence factors were included. Bap is known to mediate bacterial attachment to polystyrene and biofilm formation in S. aureus and some CoNS [77, 78].

Capsular polysaccharide production is an important virulence determinant in many invasive bacterial pathogens. Capsular polysaccharides are produced by $\sim 90 \%$ of $S$. aureus strains, and encapsulated $S$. aureus strains are more resistant to phagocytosis than the nonencapsulated strains [79]. Among the CoNS, S. haemolyticus, S. hyicus, and $S$. lentus produce a capsular polysaccharide-like surface antigen that cross-react serologically with $S$. aureus type 5 capsular polysaccharide [80].

In our genome analysis, three $S$. caprae strains carried a capsular gene operon composed of 16 genes. Even though the first four genes in this operon showed high amino acid identities to $S$. aureus cap 5ABCD, $S$. caprae's capsular polysaccharide might form a different structure compared with $S$. aureus's capsular polysaccharide. The $S$. caprae cap operon contained capHIOM homologues, and the cap operon encoded putative polysaccharide modification enzymes such as glycosyltransferases, $\mathrm{O}$-acetyltransferase, and aminotransferase.

The type VII secretion system is encoded by the genomes of diverse bacterial species across the Firmicutes and Actinobacteria phyla, including S. aureus and Mycobacterium tuberculosis. The $S$. aureus type VII secretion system exports several effector proteins including EsxABCD and nuclease toxin EsaD, enabling long-term survival in abscesses [81-85]. The gene component of the type VII secretion system cluster varies among $S$. aureus strains, but the gene cluster of $S$. caprae showed high similarity to those of $S$. aureus, e.g. there were $60 \%$ identity and $94 \%$ similarity of EsaA between S. caprae JMUB898 and S. aureus MRSA252. The $S$. caprae type VII secretion system contained eight genes encoding four membrane-associated proteins (EsaA, EssAB, and EssC), two soluble cytosolic proteins EsaBC, and two secreted virulence factors EsxAB.

The utilization of trehalose as a carbon source is a key characteristic of $S$. caprae because most S. epidermidis and $S$. capitis strains cannot use trehalose as a carbon source $[9,86]$. Our genome analysis confirmed that the trehalose-specific PTS system was found only in $S$. caprae genomes but not in S. epidermidis and S. capitis.

\section{Biofilm formation capacity of S. caprae}

In order to assess whether S. caprae strains can produce biofilms, we carried out biofilm assays in comparison with other staphylococcal species that are well known as biofilm producers. Four S. epidermidis, four S. capitis, five $S$. caprae, and two $S$. aureus strains were compared (Fig. 8). All strains tested formed biofilm on a plastic surface and the biofilm formation was induced by adding $1 \%$ glucose. However, the levels of biofilm formation varied among strains. Two S. aureus strains (N315 and MW2), two $S$. epidermidis strains (RP62a and JMUB051), and one S. capitis strain (JMUB603) produced higher amounts of biofilm mass on a plastic surface than the other strains. The $S$. caprae strains produced detectable but weaker biofilms.

\section{Conclusions}

Complete whole-genome sequencing and comparative genome analysis revealed that $S$. caprae was highly similar to S. epidermidis and S. capitis. Moreover, these three coagulase-negative staphylococcal species commonly shared many virulence genes represented by biofilm formation-associated genes, which encode factors that may tolerate having similar pathogenesis features, for example, causing infections associated with indwelling medical devices or catheter use. These virulence factors can be considered as the main characteristics of the epidermidis cluster group. We found that $S$. caprae was differentiated from $S$. epidermidis and $S$. capitis by 


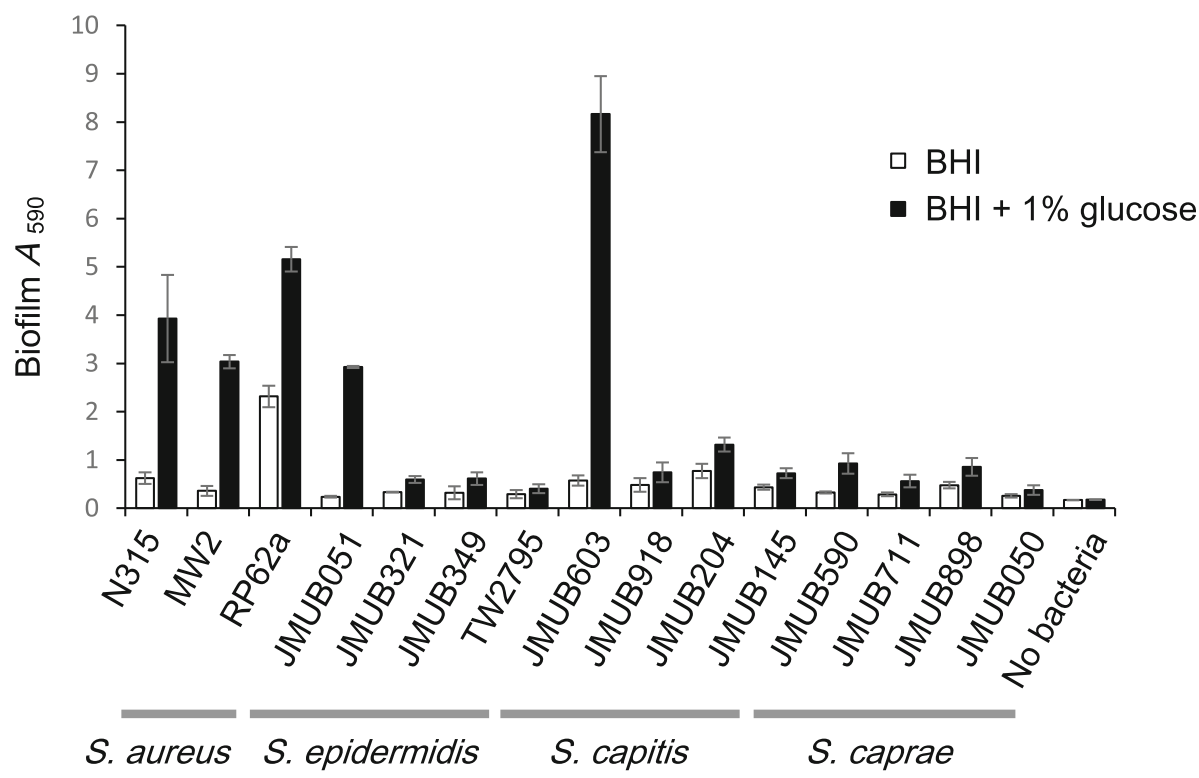

Fig. 8 Biofilm formation on a plastic surface. The amount of biofilm on a plastic surface was assessed using crystal violet stain after a 24-h incubation in $\mathrm{BHI}$ broth with or without glucose in a plastic titer plate

species-specific virulence factors, capsular polysaccharides and type VII secretion system, which had not been found in S. epidermidis and S. capitis genomes, but were found in S. aureus genomes. The role of these factors on pathogenesis in humans remains largely unknown. It can be speculated that these $S$. caprae-specific factors may confer pathogenicity in animals such as goats.

\section{Methods}

\section{Bacterial strains}

All three methicillin-resistant $S$. caprae strains JMUB145, JMUB898, and JMUB590 were isolated from Jichi Medical University Hospital in Japan in 2015. Both S. caprae JMUB145 and JMUB898 are clinical strains; the former was isolated from the blood culture of woman with a fever during the course of chemotherapy treatment for uterine cancer, while the latter was isolated from man with graft infection. In contrast, $S$. caprae JMUB590 was a colonizing isolate obtained from a nasal swab during screening for MRSA colonization of a patient admitted to Jichi Medical University Hospital in 2015. S. caprae strains were cultivated at $37^{\circ} \mathrm{C}$ in tryptic soy broth (TSB), brain heart infusion (BHI) broth, or on tryptic soy agar (Becton Dickinson Co., Ltd., Sparks, MD). The strains were stored at $-80{ }^{\circ} \mathrm{C}$ in $50 \%$ glycerol (Wako Pure Chemical Industries, Ltd., Tokyo, Japan). We analyzed biofilm formation of three $S$. epidermidis strains (JMUB051, JMUB321, and JMUB349), three $S$. capitis strains (JMUB603, JMUB918, and JMUB204) and two S. caprae strains (JMUB711 and JMUB050), all of which were isolated from patients in Jichi Medical University Hospital between 2015 and 2016. We also performed biofilm assays using genome-sequenced strains: S. aureus N315, S. aureus MW2, S. epidermidis RP62a, and S. capitis TW2795.

\section{DNA extraction}

Overnight culture of $S$. caprae strains grown in $10 \mathrm{ml}$ of TSB at $37{ }^{\circ} \mathrm{C}$ was harvested by centrifugation with $8,000 \mathrm{rpm}$ for $5 \mathrm{~min}$. The pelleted cells were then resuspended in $3 \mathrm{ml}$ of TE buffer containing $150 \mu \mathrm{g}$ of lysostaphin (Sigma-Aldrich. Co., LLC., St Louis, MO) and $100 \mu \mathrm{g}$ of RNase A (Sigma-Aldrich. Co., LLC.). Following a 2-h incubation at $37{ }^{\circ} \mathrm{C}, 525 \mu \mathrm{l}$ of $10 \%$ SDS and $37.5 \mu \mathrm{l}$ of Proteinase $\mathrm{K}$ solution (Qiagen, Hilden, Germany) were added to the cell lysate. The mixture was then incubated at $56{ }^{\circ} \mathrm{C}$ for $2 \mathrm{~h}$. After incubation, one volume of tris-saturated phenol $(\mathrm{pH} \mathrm{8.0)}$ was added, and the resulting solution was mixed well by inverting the tube for $5 \mathrm{~min}$. After centrifugation, the aqueous phase was transferred into a new tube. An equal volume of chloroform: isoamylalcohol in the ratio of 24: 1 (vol/ vol) was added and mixed well. Following centrifugation, the aqueous phase was transferred into a new tube and a $1 / 25$ volume of $5 \mathrm{M} \mathrm{NaCl}$ and 2.5 volume of ethanol were added. After centrifugation, the DNA pellet was washed by $80 \%$ ethanol and dried briefly. TE buffer was added to dissolve the DNA. The extracted DNA was treated with RNase again and purified with a DNeasy Blood and Tissue Kit (Qiagen).

Whole genome sequencing of $S$. caprae strains Whole-genome sequencing of $S$. caprae was performed as previously described [87]. Briefly, mate-pair 
sequencing libraries were constructed from genomic DNA of $S$. caprae strains using the Nextera mate-pair sample preparation kit (Illumina, Inc., San Diego, CA, USA) without size selection. Sequencing was performed using the Illumina MiSeq platform $(2 \times 301 \mathrm{bp})$ with MiSeq reagent kit version 3 (Illumina, Inc.). The resulting 813,708, $1,058,128$, and 1,268,939 paired-end reads of JMUB898, JMUB145, and JMUB590, respectively, were subjected to quality trimming using the FASTQ toolkit version 2.0.0 with quality levels of 35 (JMUB898), 25 (JMUB145), and 35 (JMUB590). A total of 747,050 (JMUB898), 1,057,765 (JMUB145), and 1,168,116 (JMUB590) high-quality reads were then assembled with the Velvet de novo assembly version 1.2.10 algorithm. The generated assemblies composed of 24, 25, and 18 scaffolds, with the longest scaffolds reported to be $2,584,878,2,606,760$, and 2,615,026 bp in JMUB898, JMUB145, and JMUB590, respectively, which are close to the expected size of the Staphylococcus genome. Persisting gaps, 18, 23, and 14, in the three respective strains were closed by gap-spanning PCR, followed by Sanger sequencing using an ABI3130xl genetic analyzer (Applied Biosystems, Carlsbad, CA, USA) to generate a single circular genome. The genome sequences were automatically annotated with Microbial Genome Annotation Pipeline (MiGAP, https://www.migap.org/) [88] and manually extracted and annotated.

\section{Construction of a phylogenetic tree}

The phylogenetic tree of staphylococci was constructed using kSNP program version 3.021 [89]. Whole-genome analysis of phylogenies were conducted based on single-nucleotide polymorphisms (SNPs) in the complete whole-genome sequence data of 82 Staphylococcus strains including three complete genome sequences and two assembled genomes of $S$. caprae strains (Additional file 1 TableS1). To extract SNPs from sequence data, we applied k-mer 13 as the optimal value predicted by the kSNP-associated Kchooser script. A maximum parsimony tree was constructed using the majority of SNPs present in at least $75 \%$ of genomes. The phylogenetic tree was visualized by FigTree ver.1.4.3 (tree.bio.ed.ac.uk/software/figtree/).

\section{Gene content analysis}

The complete genome sequences of seven S. epidermidis (14-1-R1, 1457, ATCC12228, BPH0662, PM221, RP62A and SEI), three $S$. capitis (AYP1020, CR01 and TW2795), and three $S$. caprae strains (JMUB145, JMUB590 and JMUB898) (Additional file 1 TableS1) were used for the identification of pan and core genomes. First, coding DNA sequences (CDSs) harbored on the mobile genomic islands such as SCCmec, transposons, and prophages were extracted from gene sets of each species and were categorized as accessory genes.
The gene sets from paired strains of each species were then compared by pairwise blastp analysis using in silico Molecular Cloning Genomics Edition ver. 6.0.11D (in silico biology, Inc. Yokohama, Japan) and those sharing an amino acid sequence of over $50 \%$ identity and over $50 \%$ length by the blastp search (Additional file $2 \mathrm{Ta}$ bleS2) were defined as species-conserved genes for the strain. Next, in order to identify the gene set conserved among all three species, pairwise blastp analysis was performed on each species-conserved gene set of S. epidermidis, S. capitis, and S. caprae (Additional file 2 TableS2). Circular representation of Staphylococcus chromosomes and whole-genome comparison were performed by BLAST Ring Image Generator v0.95 based on blastn analysis [19]. Pairwise blastn analysis for SCCmec regions were carried out using Easyfig ver. 2.2.2 [90]. Dot plot analysis was performed using in silico Molecular Cloning Genomics Edition ver. 6.0.11D. A heat map derived from the pairwise amino acid identity matrix tables calculated by in silico Molecular Cloning Genomics Edition ver 6.0.11D was generated using the hierarchical clustering method calculated by Cluster 3.0 [91] and visualized by Java Treeview ver 1.1.6r4 [92].

\section{Biofilm assays}

Biofilm assays were performed as previously described [93]. Briefly, the overnight culture in BHI broth was 1,000-fold diluted with fresh BHI broth supplemented with (or without) $1 \%$ glucose. After $24 \mathrm{~h}$ at $37^{\circ} \mathrm{C}$ incubation in a TrueLine Cell Culture 96-well plate (Nippon Genetics, Tokyo, Japan), the bacterial culture supernatant was discarded. After the wells were washed with $100 \mu \mathrm{l}$ of Dulbecco's PBS (-) three times, the biofilm was stained with $1 \%$ crystal violet (Nacalai Tesque) $(w /$ $v o l)$ at room temperature for $30 \mathrm{~min}$. The dye solution was discarded, and the plate was washed with $100 \mu \mathrm{l}$ of Dulbecco's PBS (-) three times. The dye was extracted from biofilm with $70 \%$ ethanol containing $1 \% \mathrm{HCl}$. The $\mathrm{OD}_{590}$ was measured with a VersaMax tunable microplate reader (Molecular Devices, CA).

\section{Nucleotide sequence accession number}

The whole genome sequences of $S$. caprae JMUB145, JMUB590 and JMUB898 were deposited in GenBank (NCBI) under the accession numbers AP018585, AP018586 and AP018587, respectively.

\section{Additional files}

Additional file 1: Table S1. List of Staphylococcus strains used in phylogenetic analysis (XLSX $14 \mathrm{~kb}$ )

Additional file 2: Table S2. Genome information of S. caprae JMUB898, S. caprae JMUB590, S. caprae JMUB145, S. epidermidis RP62a and S. capitis TW2795. (XLSX 1515 kb) 


\section{Abbreviations}

BHI: Brain heart infusion; CoNS: Coagulase-negative staphylococci; PIA: Polysaccharide intracellular adhesin; PSM: Phenol soluble moduline; SCCmec: Staphylococcus Cassette Chromosome mec; SNPs: Single-nucleotide polymorphisms; TSB: Tryptic soy broth; WTA: Wall teichoic acid

\section{Acknowledgments}

Not applicable.

\section{Funding}

This work was supported by JSPS KAKENHI Grant Number 15 H05654 (SW), 26460536 (LC), Takeda Science Foundation (SW), GSK Japan Research Grant 2015 (SW), JSPS International Research Fellow $17 F 17713$ (BC) and Japan Agency for Medical Research and Development (AMED) J-PRIDE Grant JP19fm0208028 (LC). The funders had no role in study design, data collection and analysis, decision to publish and preparation of the manuscript.

\section{Availability of data and materials}

All data generated are available in the DDBJ Sequence Read Archive and are included in the supplement materials. http://ddbj.nig.ac.jp/DRASearch/ query?acc $=$ DRA007414

\section{Authors' contributions}

SW and LC designed the study. SW, YA, XET, LFY, TB, KT, BC, YS and KK performed experiments and analyzed data. TS coordinate the clinical sample collection. SW prepared figures and drafted the manuscript. YA, XET, LFY, TB, $K T, B C, Y S, K K, T S$ and LC edited and revised the manuscript. All authors have read and approved the final manuscript.

\section{Ethics approval and consent to participate}

Ethics approval and consent to participate were not required. Bacterial isolates were taken from Jichi Medical University Hospital as part of the standard patient care and used anonymously. (To Editors: For consideration on this issue, ethics approval is not required following the ethical guidelines for medical and health research involving human subjects by Ministry of Health, Labour and Welfare, Japan since this study analyzed bacteria which were isolated as a clinical specimen and patients' personal health information could not be accessed (http://www.mhlw.go.jp/stf/ seisakunitsuite/bunya/hokabunya/kenkyujigyou/i-kenkyu/index.html).).

\section{Consent for publication}

Not applicable.

\section{Competing interests}

The authors declare that they have no competing interests.

\section{Publisher's Note}

Springer Nature remains neutral with regard to jurisdictional claims in published maps and institutional affiliations.

\section{Received: 10 May 2018 Accepted: 18 October 2018}

\section{Published online: 08 November 2018}

\section{References}

1. Evans CA, Smith WM, Johnston EA, Giblett ER. Bacterial flora of the normal human skin. J Invest Dermatol. 1950;15:305-24.

2. Marples MJ. The normal microbial flora of the skin. Soc Appl Bacteriol Symp Ser. 1974;3:7-12

3. Costello EK, Lauber CL, Hamady M, Fierer N, Gordon Jl, Knight R. Bacterial community variation in human body habitats across space and time. Science. 2009;326:1694-7.

4. Grice EA, Kong HH, Conlan S, Deming CB, Davis J, Young AC, Bouffard GG, Blakesley RW, Murray PR, Green ED, et al. Topographical and temporal diversity of the human skin microbiome. Science. 2009;324:1190-2.

5. Findley K, Oh J, Yang J, Conlan S, Deming C, Meyer JA, Schoenfeld D, Nomicos E, Park M, Kong HH, et al. Topographic diversity of fungal and bacterial communities in human skin. Nature. 2013;498:367-70.

6. Grice EA, Segre JA. The skin microbiome. Nat Rev Microbiol. 2011;9:244-53.

7. Becker K, Heilmann C, Peters G. Coagulase-negative staphylococci. Clin Microbiol Rev. 2014;27:870-926.
8. Arciola CR, Campoccia D, An YH, Baldassarri L, Pirini V, Donati ME, Pegreffi F, Montanaro L. Prevalence and antibiotic resistance of 15 minor staphylococcal species colonizing orthopedic implants. Int J Artif Organs. 2006;29:395-401.

9. Devrise L, Poutrel B, Kilpperbalz R, Schleifer K. Staphylococcus gallinarum and Staphylococcus caprae, 2 new species from animals. Int I Syst Bacteriol. 1983; 33:480-6.

10. Seng P, Barbe M, Pinelli PO, Gouriet F, Drancourt M, Minebois A, Cellier N, Lechiche C, Asencio G, Lavigne JP, et al. Staphylococcus caprae bone and joint infections: a re-emerging infection? Clin Microbiol Infect. 2014;20:1052-8.

11. Vandenesch F, Eykyn SJ, Bes M, Meugnier H, Fleurette J, Etienne J. Identification and ribotypes of Staphylococcus caprae isolates isolated as human pathogens and from goat milk. J Clin Microbiol. 1995;33:888-92.

12. Shuttleworth R, Behme RJ, McNabb A, Colby WD. Human isolates of Staphylococcus caprae: association with bone and joint infections. J Clin Microbiol. 1997;35:2537-41.

13. Allignet J, Galdbart JO, Morvan A, Dyke KG, Vaudaux P, Aubert S, Desplaces $\mathrm{N}$, el Solh N. Tracking adhesion factors in Staphylococcus caprae strains responsible for human bone infections following implantation of orthopaedic material. Microbiology. 1999;145:2033-42.

14. Ross TL, Fuss EP, Harrington SM, Cai M, Perl TM, Merz WG. Methicillinresistant Staphylococcus caprae in a neonatal intensive care unit. J Clin Microbiol. 2005;43:363-7.

15. Lamers RP, Muthukrishnan G, Castoe TA, Tafur S, Cole AM, Parkinson CL. Phylogenetic relationships among Staphylococcus species and refinement of cluster groups based on multilocus data. BMC Evol Biol. 2012;12:171.

16. Vuong C, Otto M. Staphylococcus epidermidis infections. Microbes Infect. 2002;4:481-9.

17. Kumar R, Jangir PK, Das J, Taneja B, Sharma R. Genome analysis of Staphylococcus capitis TE8 reveals repertoire of antimicrobial peptides and adaptation strategies for growth on human skin. Sci Rep. 2017;7:10447.

18. Zheng B, Jiang X, Li A, Yao J, Zhang J, Hu X, Li L. Whole-genome sequence of multidrug-resistant Staphylococcus caprae strain 9557, isolated from cerebrospinal fluid. Genome Announc. 2015;3:e00718-5.

19. Alikhan NF, Petty NK, Ben Zakour NL, Beatson SA. BLAST ring image generator (BRIG): simple prokaryote genome comparisons. BMC Genomics. 2011;12:402

20. Hisata K, Ito T, Matsunaga N, Komatsu M, Jin J, Li S, Watanabe S, Shimizu T, Hiramatsu K. Dissemination of multiple MRSA clones among communityassociated methicillin-resistant Staphylococcus aureus infections from Japanese children with impetigo. J Infect Chemother. 2011;17:609-21.

21. Black CC, Solyman SM, Eberlein LC, Bemis DA, Woron AM, Kania SA. Identification of a predominant multilocus sequence type, pulsed-field gel electrophoresis cluster, and novel staphylococcal chromosomal cassette in clinical isolates of mecA-containing, methicillin-resistant Staphylococcus pseudintermedius. Vet Microbiol. 2009;139:333-8.

22. Highlander SK, Hultén KG, Qin X, Jiang H, Yerrapragada S, Mason EO, Shang Y, Williams TM, Fortunov RM, Liu Y, et al. Subtle genetic changes enhance virulence of methicillin resistant and sensitive Staphylococcus aureus. BMC Microbiol. 2007;7:99

23. Takeuchi F, Watanabe S, Baba T, Yuzawa H, Ito T, Morimoto Y, Kuroda M, Cu L, Takahashi M, Ankai A, et al. Whole-genome sequencing of Staphylococcus haemolyticus uncovers the extreme plasticity of its genome and the evolution of human-colonizing staphylococcal species. J Bacteriol. 2005;187: 7292-308.

24. Suzuki E, Kuwahara-Arai K, Richardson JF, Hiramatsu K. Distribution of mec regulator genes in methicillin-resistant Staphylococcus clinical strains. Antimicrob Agents Chemother. 1993;37:1219-26.

25. Sinlapasorn S, Lulitanond A, Angkititrakul S, Chanawong A, Wilailuckana C, Tavichakorntrakool R, Chindawong K, Seelaget C, Krasaesom M, Chartchai S, et al. SCCmec IX in meticillin-resistant Staphylococcus aureus and meticillinresistant coagulase-negative staphylococci from pigs and workers at pig farms in Khon Kaen. Thailand J Med Microbiol. 2015;64:1087-93.

26. Sadovskaya I, Vinogradov E, Li J, Jabbouri S. Structural elucidation of the extracellular and cell-wall teichoic acids of Staphylococcus epidermidis RP62A, a reference biofilm-positive strain. Carbohydr Res. 2004;339:1467-73.

27. Kocianova S, Vuong C, Yao Y, Voyich JM, Fischer ER, DeLeo FR, Otto M. Key role of poly-gamma-DL-glutamic acid in immune evasion and virulence of Staphylococcus epidermidis. J Clin Invest. 2005;115:688-94.

28. Kiedrowski MR, Kavanaugh JS, Malone CL, Mootz JM, Voyich JM, Smeltzer MS, Bayles KW, Horswill AR. Nuclease modulates biofilm formation in 
community-associated methicillin-resistant Staphylococcus aureus. PLoS One. 2011;6:e26714.

29. Wang C, Li M, Dong D, Wang J, Ren J, Otto M, Gao Q. Role of ClpP in biofilm formation and virulence of Staphylococcus epidermidis. Microbes Infect. 2007;9:1376-83.

30. Shahrooei M, Hira V, Stijlemans B, Merckx R, Hermans PW, Van Eldere J. Inhibition of Staphylococcus epidermidis biofilm formation by rabbit polyclonal antibodies against the SesC protein. Infect Immun. 2009;77:3670-8.

31. Bowden MG, Chen W, Singvall J, Xu Y, Peacock SJ, Valtulina V, Speziale P, Höök M. Identification and preliminary characterization of cell-wall-anchored proteins of Staphylococcus epidermidis. Microbiology. 2005;151:1453-64.

32. Clarke SR, Harris LG, Richards RG, Foster SJ. Analysis of Ebh, a 1.1megadalton cell wall-associated fibronectin-binding protein of Staphylococcus aureus. Infect Immun. 2002;70:6680-7.

33. Linnes JC, Ma H, Bryers JD. Giant extracellular matrix binding protein expression in Staphylococcus epidermidis is regulated by biofilm formation and osmotic pressure. Curr Microbiol. 2013;66:627-33.

34. Fey PD, Olson ME. Current concepts in biofilm formation of Staphylococcus epidermidis. Future Microbiol. 2010;5:917-33.

35. Allignet J, Aubert S, Dyke KG, El Solh N. Staphylococcus caprae strains carry determinants known to be involved in pathogenicity: a gene encoding an autolysin-binding fibronectin and the Ica operon involved in biofilm formation. Infect Immun. 2001:69:712-8.

36. Yokoi K, Sugahara K, Iguchi A, Nishitani G, Ikeda M, Shimada T, Inagaki N, Yamakawa A, Taketo A, Kodaira K. Molecular properties of the putative autolysin Atl(WM) encoded by Staphylococcus warneri M: mutational and biochemical analyses of the amidase and glucosaminidase domains. Gene. 2008:416:66-76.

37. Bourgeois I, Camiade E, Biswas R, Courtin P, Gibert L, Götz F, ChapotChartier MP, Pons JL, Pestel-Caron M. Characterization of AtlL, a bifunctional autolysin of Staphylococcus lugdunensis with $\mathrm{N}$-acetylglucosaminidase and $\mathrm{N}$-acetylmuramoyl--alanine amidase activities. FEMS Microbiol Lett. 2009; 290:105-13.

38. Marples RR, Downing DT, Kligman AM. Control of free fatty acids in human surface lipids by Corynebacterium acnes. J Invest Dermatol. 1971;56:127-31.

39. Farrell AM, Foster TJ, Holland KT. Molecular analysis and expression of the lipase of Staphylococcus epidermidis. J Gen Microbiol. 1993;139:267-77.

40. Longshaw CM, Farrell AM, Wright JD, Holland KT. Identification of a second lipase gene, gehD, in Staphylococcus epidermidis: comparison of sequence with those of other staphylococcal lipases. Microbiology. 2000;146:1419-27.

41. Lai Y, Villaruz AE, Li M, Cha DJ, Sturdevant DE, Otto M. The human anionic antimicrobial peptide dermcidin induces proteolytic defence mechanisms in staphylococci. Mol Microbiol. 2007;63:497-506.

42. Park PW, Rosenbloom J, Abrams WR, Mecham RP. Molecular cloning and expression of the gene for elastin-binding protein (ebpS) in Staphylococcus aureus. J Biol Chem. 1996;271:15803-9.

43. Roche FM, Downer R, Keane F, Speziale P, Park PW, Foster TJ. The N-terminal a domain of fibronectin-binding proteins $\mathrm{a}$ and $\mathrm{B}$ promotes adhesion of Staphylococcus aureus to elastin. J Biol Chem. 2004;279:38433-40.

44. Nakakido M, Aikawa C, Nakagawa I, Tsumoto K. The staphylococcal elastinbinding protein regulates zinc-dependent growth/biofilm formation. J Biochem. 2014;156:155-62.

45. Heilmann C, Gerke C, Perdreau-Remington F, Götz F. Characterization of Tn917 insertion mutants of Staphylococcus epidermidis affected in biofilm formation. Infect Immun. 1996;64:277-82.

46. Heilmann C, Schweitzer O, Gerke C, Vanittanakom N, Mack D, Götz F. Molecular basis of intercellular adhesion in the biofilm-forming Staphylococcus epidermidis. Mol Microbiol. 1996;20:1083-91.

47. Vuong C, Voyich JM, Fischer ER, Braughton KR, Whitney AR, DeLeo FR, Otto M. Polysaccharide intercellular adhesin (PIA) protects Staphylococcus epidermidis against major components of the human innate immune system. Cell Microbiol. 2004;6:269-75.

48. Gerke C, Kraft A, Süssmuth R, Schweitzer O, Götz F. Characterization of the $\mathrm{N}$-acetylglucosaminyltransferase activity involved in the biosynthesis of the Staphylococcus epidermidis polysaccharide intercellular adhesin. J Biol Chem. 1998:273:18586-93.

49. Cramton SE, Gerke C, Schnell NF, Nichols WW, Götz F. The intercellular adhesion (ica) locus is present in Staphylococcus aureus and is required for biofilm formation. Infect Immun. 1999;67:5427-33.

50. Chokr A, Watier D, Eleaume H, Pangon B, Ghnassia JC, Mack D, Jabbouri S. Correlation between biofilm formation and production of polysaccharide intercellular adhesin in clinical isolates of coagulase-negative staphylococci. Int J Med Microbiol. 2006;296:381-8.

51. Frank KL, Hanssen AD, Patel R. icaA is not a useful diagnostic marker for prosthetic joint infection. J Clin Microbiol. 2004;42:4846-9.

52. Kloos WE, Bannerman TL. Update on clinical significance of coagulasenegative staphylococci. Clin Microbiol Rev. 1994;7:117-40.

53. Pelz A, Wieland KP, Putzbach K, Hentschel P, Albert K, Götz F. Structure and biosynthesis of staphyloxanthin from Staphylococcus aureus. J Biol Chem. 2005;280:32493-8.

54. Froeliger EH, Fives-Taylor P. Streptococcus parasanguis fimbria-associated adhesin fap 1 is required for biofilm formation. Infect Immun. 2001;69:2512-9.

55. Bensing BA, Sullam PM. An accessory sec locus of Streptococcus gordonii is required for export of the surface protein GspB and for normal levels of binding to human platelets. Mol Microbiol. 2002;44:1081-94.

56. Schumacher-Perdreau F, Heilmann C, Peters G, Götz F, Pulverer G. Comparative analysis of a biofilm-forming Staphylococcus epidermidis strain and its adhesion-positive, accumulation-negative mutant M7. FEMS Microbiol Lett. 1994;117:71-8.

57. Hussain M, Herrmann M, von Eiff C, Perdreau-Remington F, Peters G. A 140kilodalton extracellular protein is essential for the accumulation of Staphylococcus epidermidis strains on surfaces. Infect Immun. 1997;65:519-24.

58. Williams R, Henderson B, Sharp $\sqcup$, Nair SP. Identification of a fibronectin-binding protein from Staphylococcus epidermidis. Infect Immun. 2002;70:6805-10.

59. Christner M, Franke GC, Schommer NN, Wendt U, Wegert K, Pehle P, Kroll G, Schulze C, Buck F, Mack D, et al. The giant extracellular matrix-binding protein of Staphylococcus epidermidis mediates biofilm accumulation and attachment to fibronectin. Mol Microbiol. 2010;75:187-207.

60. Nilsson M, Frykberg L, Flock Jl, Pei L, Lindberg M, Guss B. A fibrinogen-binding protein of Staphylococcus epidermidis. Infect Immun. 1998;66:2666-73.

61. McCrea KW, Hartford O, Davis S, Eidhin DN, Lina G, Speziale P, Foster TJ, Höök M. The serine-aspartate repeat (Sdr) protein family in Staphylococcus epidermidis. Microbiology. 2000;146:1535-46.

62. Guo B, Zhao X, Shi Y, Zhu D, Zhang Y. Pathogenic implication of a fibrinogen-binding protein of Staphylococcus epidermidis in a rat model of intravascular-catheter-associated infection. Infect Immun. 2007;75:2991-5.

63. Dubin G, Chmiel D, Mak P, Rakwalska M, Rzychon M, Dubin A. Molecular cloning and biochemical characterisation of proteases from Staphylococcus epidermidis. Biol Chem. 2001;382:1575-82.

64. Moon JL, Banbula A, Oleksy A, Mayo JA, Travis J. Isolation and characterization of a highly specific serine endopeptidase from an oral strain of Staphylococcus epidermidis. Biol Chem. 2001;382:1095-9.

65. Ohara-Nemoto Y, Ikeda Y, Kobayashi M, Sasaki M, Tajika S, Kimura S. Characterization and molecular cloning of a glutamyl endopeptidase from Staphylococcus epidermidis. Microb Pathog. 2002;33:33-41.

66. Iwase T, Uehara Y, Shinji H, Tajima A, Seo H, Takada K, Agata T, Mizunoe Y. Staphylococcus epidermidis Esp inhibits Staphylococcus aureus biofilm formation and nasal colonization. Nature. 2010:465:346-9.

67. Emmett $\mathrm{M}$, Kloos WE. The nature of arginine auxotrophy in cutaneous populations of staphylococci. J Gen Microbiol. 1979;110:305-14.

68. Wang Y, Kuo S, Shu M, Yu J, Huang S, Dai A, Two A, Gallo RL, Huang CM. Staphylococcus epidermidis in the human skin microbiome mediates fermentation to inhibit the growth of Propionibacterium acnes: implications of probiotics in acne vulgaris. Appl Microbiol Biotechnol. 2014;98:411-24.

69. Watanabe S, Zimmermann M, Goodwin MB, Sauer U, Barry CE, Boshoff HI. Fumarate reductase activity maintains an energized membrane in anaerobic Mycobacterium tuberculosis. PLoS Pathog. 2011;7:e1002287.

70. Götz F, Perconti S, Popella P, Werner R, Schlag M. Epidermin and gallidermin: Staphylococcal lantibiotics. Int J Med Microbiol. 2014;304:63-71.

71. Schnell N, Engelke G, Augustin J, Rosenstein R, Ungermann V, Götz F, Entian $\mathrm{KD}$. Analysis of genes involved in the biosynthesis of lantibiotic epidermin. Eur J Biochem. 1992;204:57-68.

72. Schnell N, Entian KD, Schneider U, Götz F, Zähner H, Kellner R, Jung G. Prepeptide sequence of epidermin, a ribosomally synthesized antibiotic with four sulphide-rings. Nature. 1988;333:276-8.

73. Schnell N, Entian KD, Götz F, Hörner T, Kellner R, Jung G. Structural gene isolation and prepeptide sequence of gallidermin, a new lanthionine containing antibiotic. FEMS Microbiol Lett. 1989;49:263-7.

74. Daly KM, Upton M, Sandiford SK, Draper LA, Wescombe PA, Jack RW, O'Connor PM, Rossney A, Götz F, Hill C, et al. Production of the Bsa lantibiotic by community-acquired Staphylococcus aureus strains. J Bacteriol. 2010;192:1131-42. 
75. Siboo IR, Chambers HF, Sullam PM. Role of SraP, a serine-rich surface protein of Staphylococcus aureus, in binding to human platelets. Infect Immun. 2005;73:2273-80.

76. Sullam P. Host-pathogen interactions in the development of bacterialendocarditis. Curr Opin Infect Dis. 1994;7:304-9.

77. Cucarella C, Solano C, Valle J, Amorena B, Lasa I, Penadés JR. Bap, a Staphylococcus aureus surface protein involved in biofilm formation. J Bacteriol. 2001;183:2888-96.

78. Tormo MA, Knecht E, Götz F, Lasa I, Penadés JR. Bap-dependent biofilm formation by pathogenic species of Staphylococcus: evidence of horizontal gene transfer? Microbiology. 2005;151:2465-75.

79. Thakker M, Park JS, Carey V, Lee JC. Staphylococcus aureus serotype 5 capsular polysaccharide is antiphagocytic and enhances bacterial virulence in a murine bacteremia model. Infect Immun. 1998;66:5183-9.

80. Poutrel B, Mendolia C, Sutra L, Fournier JM. Reactivity of coagulase-negative staphylococci isolated from cow and goat milk with monoclonal antibodies to Staphylococcus aureus capsular polysaccharide types 5 and 8. I Clin Microbiol. 1990;28:358-60.

81. Burts ML, Williams WA, DeBord K, Missiakas DM. EsxA and EsxB are secreted by an ESAT-6-like system that is required for the pathogenesis of Staphylococcus aureus infections. Proc Natl Acad Sci U S A. 2005;102:1169-74.

82. Kneuper H, Cao ZP, Twomey KB, Zoltner M, Jäger F, Cargill JS, Chalmers J, van der Kooi-Pol MM, van Dij JM, Ryan RP, et al. Heterogeneity in ess transcriptional organization and variable contribution of the Ess/type VII protein secretion system to virulence across closely related Staphylocccus aureus strains. Mol Microbiol. 2014:93:928-43.

83. Wang Y, Hu M, Liu Q, Qin J, Dai Y, He L, Li T, Zheng B, Zhou F, Yu K, et al. Role of the ESAT-6 secretion system in virulence of the emerging communityassociated Staphylococcus aureus lineage ST398. Sci Rep. 2016;6:25163.

84. Cao Z, Casabona MG, Kneuper H, Chalmers JD, Palmer T. The type VII secretion system of Staphylococcus aureus secretes a nuclease toxin that targets competitor bacteria. Nat Microbiol. 2016;2:16183.

85. Lopez MS, Tan IS, Yan D, Kang J, McCreary M, Modrusan Z, Austin CD, Xu M Brown EJ. Host-derived fatty acids activate type VII secretion in Staphylococcus aureus. Proc Natl Acad Sci U S A. 2017:114:11223-8.

86. Kloos W, Schleifer K. Isolation and characterization of Staphylocococci from human skin. 2. Descriptions of 4 new species - Staphylococcus warneri, Staphylococcus capitis, Staphylococcus hominis, and Staphylococcus simulans. Int J Syst Bacteriol. 1975;25:62-79.

87. Watanabe S, Sasahara T, Arai N, Sasaki K, Aiba Y, Sato'o Y, Cui L. Complete genome sequence of Streptococcus pyogenes strain JMUB1235 isolated from an acute Phlegmonous gastritis patient. Genome Announc. 2016;4:e01133-16.

88. Sugawara H, Ohyama A, Mori H, Kurokawa K. Microbial Genome Annotation Pipeline (MiGAP) for diverse users. The 20th International Conference on Genome Informatics (GIW2009). Yokohama: Poster and Software Demonstrations; 2009. S001-001-002

89. Gardner SN, Slezak T, Hall BG. KSNP3.0: SNP detection and phylogenetic analysis of genomes without genome alignment or reference genome. Bioinformatics. 2015;31:2877-8.

90. Sullivan MJ, Petty NK, Beatson SA. Easyfig: a genome comparison visualizer. Bioinformatics. 2011;27:1009-10.

91. de Hoon M, Imoto S, Nolan J, Miyano S. Open source clustering software. Bioinformatics. 2004;20:1453-4.

92. Saldanha A. Java Treeview-extensible visualization of microarray data. Bioinformatics. 2004;20:3246-8.

93. Sato'o Y, Hisatsune J, Yu L, Sakuma T, Yamamoto T, Sugai M. Tailor-made gene silencing of Staphylococcus aureus clinical isolates by CRISPR interference. PLoS One. 2018;13:e0185987.

\section{Ready to submit your research? Choose BMC and benefit from:}

- fast, convenient online submission

- thorough peer review by experienced researchers in your field

- rapid publication on acceptance

- support for research data, including large and complex data types

- gold Open Access which fosters wider collaboration and increased citations

- maximum visibility for your research: over $100 \mathrm{M}$ website views per year

At BMC, research is always in progress.

Learn more biomedcentral.com/submissions 